PREPARED FOR THE U.S. DEPARTMENT OF ENERGY, UNDER CONTRACT DE-AC02-76CH03073

PPPL-3598

PPPL-3598

UC-70

Enhancement of Mode-converted Electron Bernstein

Wave Emission during NSTX H-mode Plasmas

by

G. Taylor, P.C. Efthimion, B. Jones, B.P. LeBlanc, and R. Maingi

August 2001

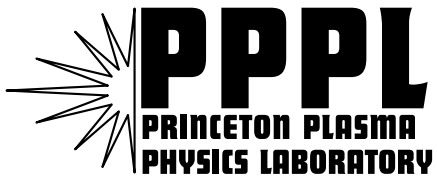

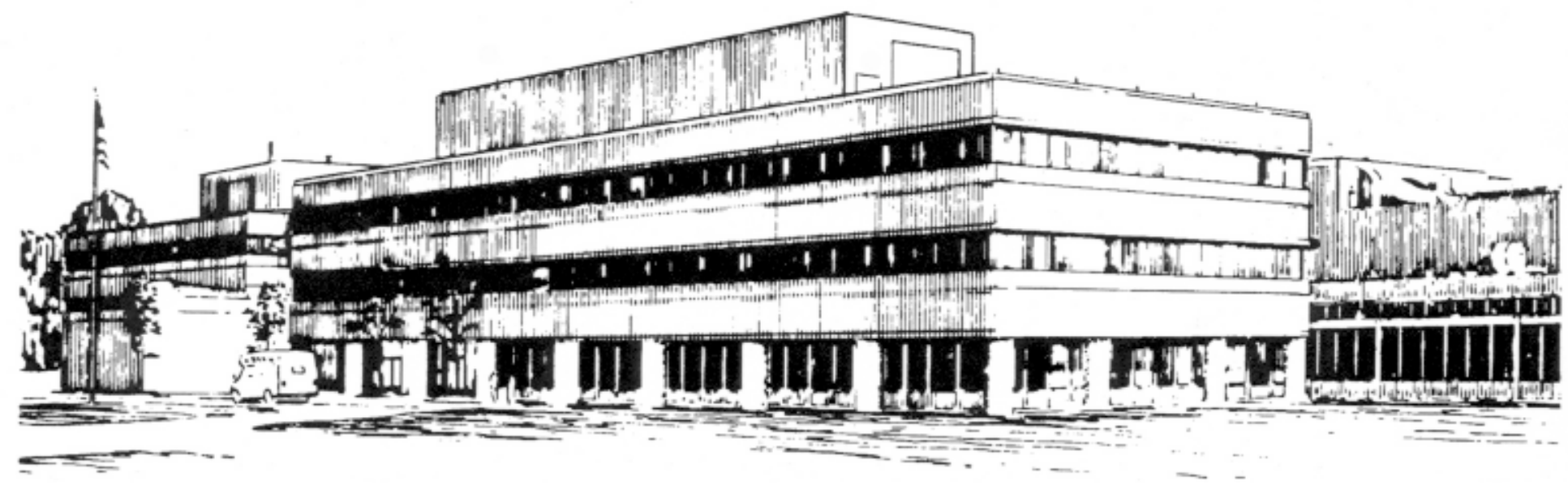

PRINCETON PLASMA PHYSICS LABORATORY PRINCETON UNIVERSITY, PRINCETON, NEW JERSEY 


\section{PPPL Reports Disclaimer}

This report was prepared as an account of work sponsored by an agency of the United States Government. Neither the United States Government nor any agency thereof, nor any of their employees, makes any warranty, express or implied, or assumes any legal liability or responsibility for the accuracy, completeness, or usefulness of any information, apparatus, product, or process disclosed, or represents that its use would not infringe privately owned rights. Reference herein to any specific commercial product, process, or service by trade name, trademark, manufacturer, or otherwise, does not necessarily constitute or imply its endorsement, recommendation, or favoring by the United States Government or any agency thereof. The views and opinions of authors expressed herein do not necessarily state or reflect those of the United States Government or any agency thereof.

\section{Availability}

This report is posted on the U.S. Department of Energy's Princeton Plasma Physics Laboratory Publications and Reports web site in Calendar Year 2001. The home page for PPPL Reports and Publications is: http://www.pppl.gov/pub_report/

DOE and DOE Contractors can obtain copies of this report from:

U.S. Department of Energy

Office of Scientific and Technical Information

DOE Technical Information Services (DTIS)

P.O. Box 62

Oak Ridge, TN 37831

Telephone: (865) 576-8401

Fax: (865) 576-5728

Email: reports@adonis.osti.gov

This report is available to the general public from:

National Technical Information Service

U.S. Department of Commerce

5285 Port Royal Road

Springfield, VA 22161

Telephone: 1-800-553-6847 or

(703) 605-6000

Fax: (703) 321-8547

Internet: http://www.ntis.gov/ordering.htm 


\title{
ENHANCEMENT OF MODE-CONVERTED ELECTRON BERNSTEIN WAVE EMISSION DURING NSTX H-MODE PLASMAS
}

\author{
G. Taylor, P.C. Efthimion, B. Jones, B.P. LeBlanc \\ Princeton Plasma Physics Laboratory, Princeton, New Jersey 08543 \\ R. Maingi \\ Oak Ridge National Laboratory, Oak Ridge, Tennessee 08731
}

\begin{abstract}
A sudden, threefold increase in emission from fundamental electrostatic electron Bernstein waves (EBW) which mode convert and tunnel to the electromagnetic X-mode has been observed during H-mode transitions on the NSTX spherical torus plasma. The mode-converted EBW emission viewed normal to the magnetic field on the plasma midplane increases when the density profile steepens in the vicinity of the mode conversion layer, which is located in the plasma scrape off. The measured conversion efficiency during the H-mode is consistent with the calculated EBW to X-mode conversion efficiency derived using edge density data. Calculations indicate that there may also be a small residual contribution to the measured Xmode electromagnetic radiation from polarization-scrambled, O-mode emission, converted from EBWs.
\end{abstract}

PACS\# 52.55.Fa, 52.35.Hr 


\section{INTRODUCTION}

Abrupt transitions to a high energy and particle confinement (H-mode) regime [1] have now been reported on several spherical torus (ST) plasma devices [2-4]. Because of their improved confinement characteristics, H-mode plasmas offer the possibility of more efficient cost effective nuclear fusion reactors. ST plasma devices, such as NSTX [5], are characterized by relatively high electron densities $\left(1-5 \times 10^{19} \mathrm{~m}^{-3}\right)$ and low confining magnetic fields (< $0.6 \mathrm{~T}$ ), so that the electron plasma frequency normally far exceeds the electron cyclotron frequency. As a result, fundamental and low harmonic electron cyclotron emission (ECE) cannot propagate in ST plasmas, so that diagnostic and heating techniques that rely on ECE cannot be used. Electron Bernstein waves (EBW) can readily propagate in ST plasmas, they have no high density cutoffs and they exhibit strong absorption at the electron cyclotron resonances [6]. These properties make EBWs potentially attractive as a tool for measuring local electron temperature and for local electron heating and current drive for ST plasmas. However, EBWs cannot propagate beyond the upper hybrid resonance (UHR) that surrounds an ST plasma. There are two potential EBW conversion processes to electromagnetic modes that can be employed to indirectly access the EBW emission inside the plasma. The first process involves the conversion of EBWs to the slow X-mode at the UHR [6-8]. The left hand cutoff of the slow X-mode, the UHR, and the right hand cutoff of the fast X-mode form a cutoffresonance-cutoff triplet allowing the slow X-mode to tunnel through the UHR to the fast Xmode. In this paper we will refer to this as $\mathrm{B}-\mathrm{X}$ mode conversion. The maximum B-X conversion efficiency for $\mathrm{k}_{/ /}=0$ is given by [6]:

$$
C_{\max }=4 e^{-\pi \eta}\left(1-e^{-\pi \eta}\right)
$$

where $\eta$ is the tunneling parameter. For magnetic scale lengths much greater than the density scale length at the UHR [6]:

$$
\begin{gathered}
\eta \approx\left[\omega_{c e} L_{n} / c \alpha\right]\left(\sqrt{1+\alpha^{2}}-1\right)^{1 / 2} \\
\text { where: } \quad \alpha=\left[\omega_{p e} / \omega_{c e}\right]_{U H R} \text { and } L_{n}=\left|\frac{n_{e}}{d n_{e} / d R}\right|_{U H R}
\end{gathered}
$$

Here $\omega_{c e}$ and $\omega_{p e}$ are the electron cyclotron frequency and electron plasma frequency, respectively, $n_{e}$ is the electron density and $c$ is the velocity of light. As can be seen from 
equations (1) and (2), the B-X mode conversion efficiency is very sensitive to the electron density scale length at the UHR layer where the mode conversion and tunneling occurs. On NSTX, the maximum mode conversion efficiency typically occurs for $\mathrm{L}_{\mathrm{n}} \sim 0.5-1 \mathrm{~cm}$.

The second mode conversion process requires the coincidence of the $\mathrm{X}$-mode and O-mode cutoffs [9-13]. This process, referred to here as B-X-O mode conversion, has been previously studied on Wendelstein 7-AS [14,15] and requires an oblique view of the plasma at a specific angle. The $\mathrm{B}-\mathrm{X}-\mathrm{O}$ emission leaves the plasma through an angular window with a transmission function given by $[11,13]$ :

$$
T\left(N_{\perp}, N_{/ /}\right)=\exp \left\{-\pi k_{o} L_{n} \sqrt{(Y / 2)}\left[2(1+Y)\left(N_{/ /, \text {opt }}-N_{/ /}\right)^{2}+N_{\perp}^{2}\right]\right\}
$$

where: $N_{/ /, \text {opt }}^{2}=[Y /(Y+1)], Y=\left(\omega_{c e} / \omega\right), \omega_{c e}$ is evaluated at the cutoff and $\omega$ is the wave frequency. For typical NSTX plasma parameters, this B-X-O emission window is located at about $\pm 35^{\circ}$ from the antenna axis in the toroidal direction. As shown in equation (3), the emission window has a width that depends on $\mathrm{L}_{\mathrm{n}}$ at the $\mathrm{X}$-mode and O-mode cutoffs. It can also potentially contribute to the measured $\mathrm{X}$-mode emission if there is polarization scrambling of the O-mode emission resulting from reflections.

The natural steepening of the edge density gradient that occurs at the $\mathrm{L}$ to $\mathrm{H}$ transition can enhance the conversion and tunneling efficiency of both the $\mathrm{B}-\mathrm{X}$ and $\mathrm{B}-\mathrm{X}-\mathrm{O}$ conversion processes if the steepening occurs in the vicinity of the EBW mode conversion layer. On NSTX, the relevant UHR for fundamental EBW B-X mode conversion normally lies in the scrape off region near the last closed flux surface, so the edge density steepening during the $\mathrm{H}$ mode might be expected to enhance the EBW conversion efficiency.

This paper reports the observation of enhanced fundamental B-X mode conversion efficiency during neutral-beam-heated NSTX H-mode plasmas with an axial magnetic field of $0.45 \mathrm{~T}$ [4]. The effective conversion efficiency was obtained from the ratio of the absolutely calibrated mode-converted EBW emission radiation temperature $\left(\mathrm{T}_{\mathrm{rad}}\right)$ to the electron temperature $\left(T_{e}\right)$ measured by laser Thomson scattering. $T_{r a d} / T_{e}$ was compared to the theoretical $\mathrm{B}-\mathrm{X}$ conversion efficiency calculated from equation (1) using edge density data from laser Thomson scattering. Recently, enhancements in B-X-O emission have also been observed during H-mode discharges in the MAST ST device at Culham, England [3]. Section II of this paper describes the experimental setup for the EBW emission measurements, section III presents an example of the EBW emission data during H-mode plasmas and section IV presents an analysis of these data and a discussion. 


\section{EXPERIMENTAL SETUP}

Mode-converted EBW emission was measured with a broadband, polarizing antenna which viewed the NSTX plasma through a vacuum window on the horizontal midplane. The antenna was oriented to collect predominantly X-mode emission during the plasma current flat top. The antenna was connected to a fast frequency scanning, $12-18 \mathrm{GHz}$, heterodyne radiometer [16]. $12-18 \mathrm{GHz}$ emission corresponds to non-Doppler shifted fundamental EBW radiation emitted from a region which extends from a major radius of 0.75 to $1.1 \mathrm{~m}$ on the horizontal midplane of NSTX, for an axial magnetic field of $0.45 \mathrm{~T}$. The EBW emission spectrum in this band was measured every $100 \mu \mathrm{s}$. The Shafranov-shifted axis was at about $0.9 \mathrm{~m}$ during these experiments, so this emission is expected to come from the core of the NSTX plasma. EBW radiation temperatures quoted in this paper were derived from an absolute calibration of the 12$18 \mathrm{GHz}$ radiometer with a chopped $77 \mathrm{~K}$ blackbody source. The magnetic field profile used to map emission data from frequency to major radius was obtained from EFIT equilibria. The emission data were mapped to major radius assuming that the emission is non-Doppler shifted fundamental EBW emission.

\section{MEASUREMENT OF EBW EMISSION DURING H-MODES}

Figure 1 shows the evolution of major plasma parameters for a NSTX discharge which exhibits a L-H transition at $0.2 \mathrm{~s}$ and an $\mathrm{H}$-mode phase which lasts $60 \mathrm{~ms}$ (shown shaded). Figure 1(a) shows the evolution of the plasma current which reaches a flat top of $1 \mathrm{MA}$ at 0.18 s. $1 \mathrm{MW}$ of neutral beam heating was injected from 0.1 to $0.26 \mathrm{~s} \mathrm{(Fig.} \mathrm{1(b)).} \mathrm{The} \mathrm{deuterium}$ wall recycling (Fig. 1 (c)) decreases suddenly at about $0.2 \mathrm{~s}$ marking the L-H transition. Figure 1(d) shows the $\mathrm{T}_{\text {rad }}$ of $16 \mathrm{GHz}$ mode-converted fundamental EBW emission, measured by the EBW radiometer. Immediately before the $\mathrm{L}-\mathrm{H}$ transition the $\mathrm{EBW} \mathrm{T}_{\text {rad }}$ is $50 \mathrm{eV}$. At the $\mathrm{L}-\mathrm{H}$ transition the EBW $\mathrm{T}_{\text {rad }}$ suddenly increases to $150 \mathrm{eV}$. Through the $\mathrm{H}$-mode phase the deuterium recycling gradually increases, while the EBW $\mathrm{T}_{\text {rad }}$ gradually decreases until the collapse of the H-mode at $0.26 \mathrm{~s}$ when the EBW emission becomes negligible. Thomson scattering electron density and temperature profiles were acquired at the three times of interest, A, B and C (indicated by vertical dashed lines in Fig. 1). Time A is well before the H-mode when the measured EBW $\mathrm{T}_{\text {rad }}$ is only a few $\mathrm{eV}$, time $\mathrm{B}$ is just before the $\mathrm{L}-\mathrm{H}$ transition when $\mathrm{T}_{\text {rad }}$ has increased to $50 \mathrm{eV}$ and time $\mathrm{C}$ is during the $\mathrm{H}$-mode when $\mathrm{T}_{\text {rad }}$ is $120 \mathrm{eV}$. 
Figure 2 shows the EBW spectrum mapped to major radius for the three times of interest marked in Fig. 1. An approximate threefold increase in EBW emission occurs at all measured frequencies between time B and C. The vertical dashed line in Fig. 2 indicates the source location of the $16 \mathrm{GHz}$ emission shown in Fig. 1, this location lies close to the magnetic axis and the peak of the emission spectrum at time $\mathrm{B}$ and $\mathrm{C}$.

Figure 3 shows the electron density profile at the three times of interest marked in Fig.1. The location of the last closed flux surface is indicated by a vertical dashed line and the relevant density for mode conversion of $16 \mathrm{GHz}$ EBW emission is indicated by the gray horizontal line. B-X mode conversion for this emission frequency occurs at $n_{e}=2.4 \times 10^{18} \mathrm{~m}^{-3}$ which lies in the scrape off, just outside the last closed flux surface. The edge density profile in the vicinity of the mode conversion location steepens significantly during the $\mathrm{H}$-mode phase of the discharge.

\section{ANALYSIS OF MODE-CONVERTED EBW EMISSION}

The measured $16 \mathrm{GHz} E B W \mathrm{~T}_{\text {rad }}$, which maps to a major radius of $0.87 \mathrm{~m}$, was compared to the $T_{e}$ measured by Thomson scattering at the three times of interest shown in Fig. 1 . $T_{\text {rad }} / T_{e}$ was taken to be a measure of the EBW mode conversion efficiency, this efficiency is plotted versus time into the discharge in Fig. 4 (filled circles). The errors in $T_{e}$ are relatively small so the error bars on $\mathrm{T}_{\text {rad }} / \mathrm{T}_{\mathrm{e}}$ are largely due to uncertainties in calibrating and mapping the EBW $\mathrm{T}_{\mathrm{rad}}$. Since the UHR lies in the NSTX scrape off an exponential fit was applied to the Thomson scattering edge density data in Fig. 3 to yield $L_{n}$ at the UHR. These $L_{n}$ values were used in equation (1) to calculate $C_{\max }$, which is plotted as open circles in Fig.4. It should be noted that there is an additional phase factor that results from the interference of the inward and outward going components of the slow X-mode [6] and this can reduce the tunneling efficiency between the slow and fast $\mathrm{X}$-mode. The fluctuations in $\mathrm{T}_{\text {rad }}$, plotted in Fig 1(d), may be caused by this interference or by electron density fluctuations in the vicinity of the UHR. During the H-mode phase of the discharge, when $\mathrm{L}_{\mathrm{n}}=1.5 \mathrm{~cm}$, the measured $\mathrm{T}_{\mathrm{rad}} / \mathrm{T}_{\mathrm{e}}$ is $11 \%$, higher than the calculated B-X mode conversion efficiency of $8 \%$, but within the relatively large uncertainties in the calculated B-X mode conversion efficiency. The exponential dependence on $L_{n}$ in the expression for the B-X mode conversion efficiency (eq. (1)) leads to large uncertainties in the calculated efficiencies plotted in Fig. 4. At the two times before the H-mode, $L_{n}$ is 2-3 times larger than during the H-mode, as a result the calculated B-X conversion efficiency is negligible at these times. B-X-O mode conversion may also contribute to the EBW radiometer signal if there is polarization scrambling of the O-mode emission due to reflections. Evidence for substantial depolarization due to reflections has already been noted during experiments with a similar antenna on CDX-U [16]. The maximum contribution from B-X-O conversion was 
calculated by combining the B-X-O angular emission window from equation (3) with the measured antenna pattern. The B-X-O conversion, with complete depolarization, could provide an additional $\mathrm{T}_{\text {rad }} / \mathrm{T}_{\mathrm{e}} \sim 3 \%$ at time $\mathrm{C}$, so that the combined total conversion efficiency (plotted as open squares in Fig. 4) is in good agreement with the measured $\mathrm{T}_{\text {rad }} / \mathrm{T}_{\mathrm{e}}$ during the H-mode. At the two times before the $\mathrm{H}$-mode there is also reasonable agreement between the measured and calculated mode conversion efficiencies if depolarized $\mathrm{B}-\mathrm{X}-\mathrm{O}$ emission is assumed to contribute to the measured emission. It should be noted that ray tracing analyses of EBW rays that lie within the acceptance angle of the antenna indicate that there can be significant Doppler shifts for rays at the edge of the antenna pattern. These Doppler shifts can significantly refract EBWs contributing to a low level of non-local emission that might be expected to dominate the measured EBW emission at low measured conversion efficiencies $(<5 \%)$.

The natural steepening that occurs in the edge density profile during H-modes is observed to significantly improve the coupling efficiency between EBWs and electromagnetic modes outside the plasma, and confirms the EBW mode conversion physics. However, the 10-15\% mode conversion efficiency measured during NSTX H-modes is insufficient in itself to justify the implementation of mode-converted EBW heating or current drive schemes, which require much higher $(>50 \%)$ conversion efficiencies to be viable. Since the fundamental EBW mode conversion layer lies outside the last closed flux surface it may be possible to increase the B-X conversion efficiency by imposing a steepened scrape off density by means of a local limiter. Experiments to investigate this possibility are presently being conducted on CDX-U and initial results are encouraging [17].

\section{ACKNOWLEDGEMENTS}

This work was supported by US Department of Energy contract no. DE-AC02$76 \mathrm{CH} 03073$ and by a US Department of Energy research grant which is part of a program to encourage innovations in magnetic fusion energy diagnostic systems. 


\section{REFERENCES}

[1] F. Wagner, et al., Phys. Rev. Lett. 49, 1408 (1982).

[2] A. Sykes, et al., Phys. Rev. Lett. 84, 495 (2000).

[3] A. Sykes, J.W. Ahn, R. Akers, et al., Physics of Plasmas 8, 2101 (2001)

[4] R. Maingi, M.G. Bell, R.E. Bell, et al., "Observations of First H-mode Transitions in NSTX", Princeton Plasma Physics Laboratory Report PPPL-3563, submitted to Phys. Rev. Lett. (2001).

[5] M. Ono, et al., Proc. $17^{\text {th }}$ IAEA Fus. Energy Conf. (IAEA, Vienna, 1999), Vol. 3, p. 1135.

[6] A.K. Ram and S.D. Schultz, Physics of Plasmas 7, 4084 (2000).

[7] S. Nakajima and H. Abe, Phys. Rev. A 38, 4373 (1988).

[8] H. Sugai, Phys. Rev. Lett. 47, 1899 (1981).

[9] J. Preinhaelter and V. Kopécky, J. Plasma Phys. 10, 1 (1973).

[10] H. Weitzner and D.B. Batchelor, Phys. Fluids 22, 1355 (1979).

[11] E. Mjølhus, J. Plasma Phys. 31, 7 (1984).

[12] S. Nakajima and H. Abe, Phys. Lett. A 124, 295 (1987).

[13] F.R. Hansen, et al., J. Plasma Phys. 39, 319 (1988).

[14] H.P. Laqua, et al., Phys. Rev. Lett. 78, 3467 (1997).

[15] H.P. Laqua, et al., Phys. Rev. Lett. 81, 2060 (1998).

[16] G. Taylor, P.C. Efthimion, B. Jones, et al., Rev. Sci. Instrum. 72, 285 (2001).

[17] G.Taylor, P.C. Efthimion, B. Jones, et al., "Electron Bernstein Wave Research on CDX-U and NSTX", Proceedings of $14^{\text {th }}$ Topical RF Conf., (Oxnard, Calif., May 2001) 


\section{FIGURE CAPTIONS}

\section{Figure 1}

Evolution of EBW emission during a NSTX discharge with an H-mode transition. Time dependence of (a) the plasma current, (b) the neutral beam power, (c) the deuterium recycling light and (d) $16 \mathrm{GHz}$ fundamental mode-converted EBW emission from the plasma core.

\section{Figure 2}

Fundamental mode converted EBW emission mapped to major radius for the three times of interest marked in Fig. 1, namely, 0.164, 0.197 and $0.230 \mathrm{~s}$.

\section{Figure 3}

Electron density profiles, measured by laser Thomson scattering for the three times of interest marked in Fig. 1.

\section{Figure 4}

Measured and calculated mode conversion efficiency for $16 \mathrm{GHz}$ EBW emission at the three times of interest shown in Fig. 1. The solid circles are the measured EBW mode conversion efficiency, the open circles are the calculated maximum B-X EBW conversion efficiency and the open squares are the calculated maximum EBW conversion efficiency, including $\mathrm{B}-\mathrm{X}$ and $\mathrm{B}-\mathrm{X}-\mathrm{O}$ conversion and assuming complete depolarization of the $\mathrm{B}-\mathrm{X}-\mathrm{O}$ emission due to reflections. 


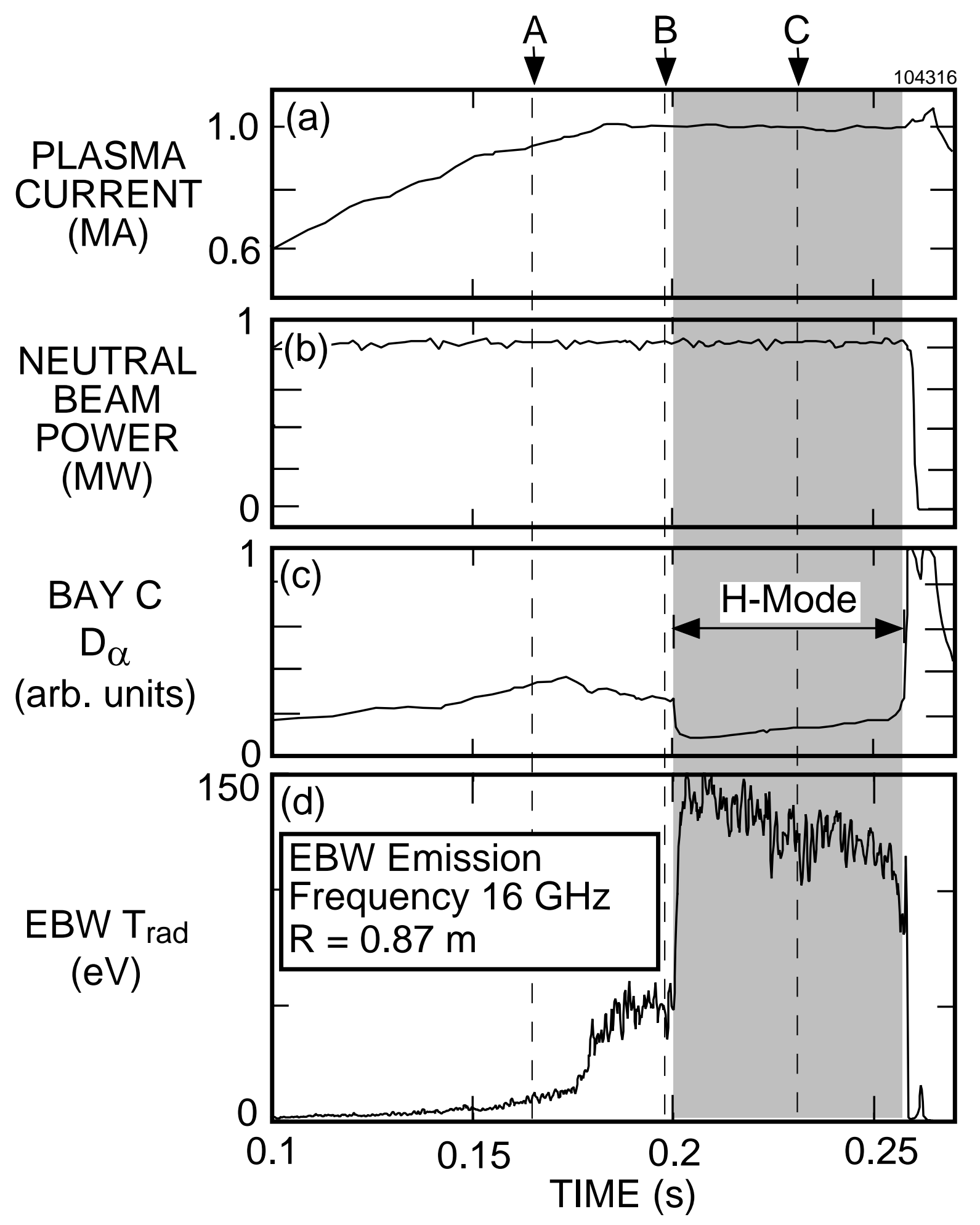




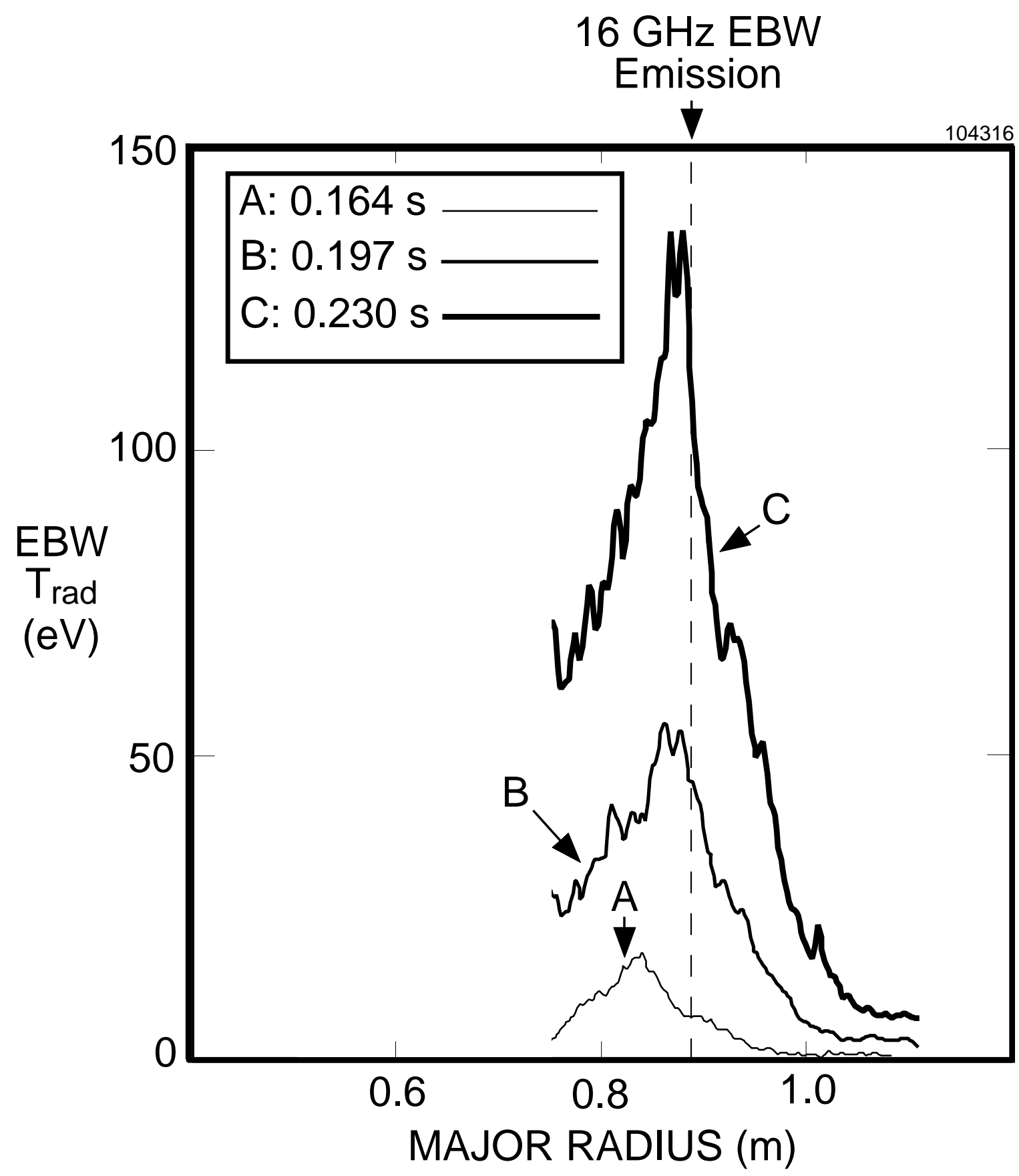


Last Closed

Flux Surface

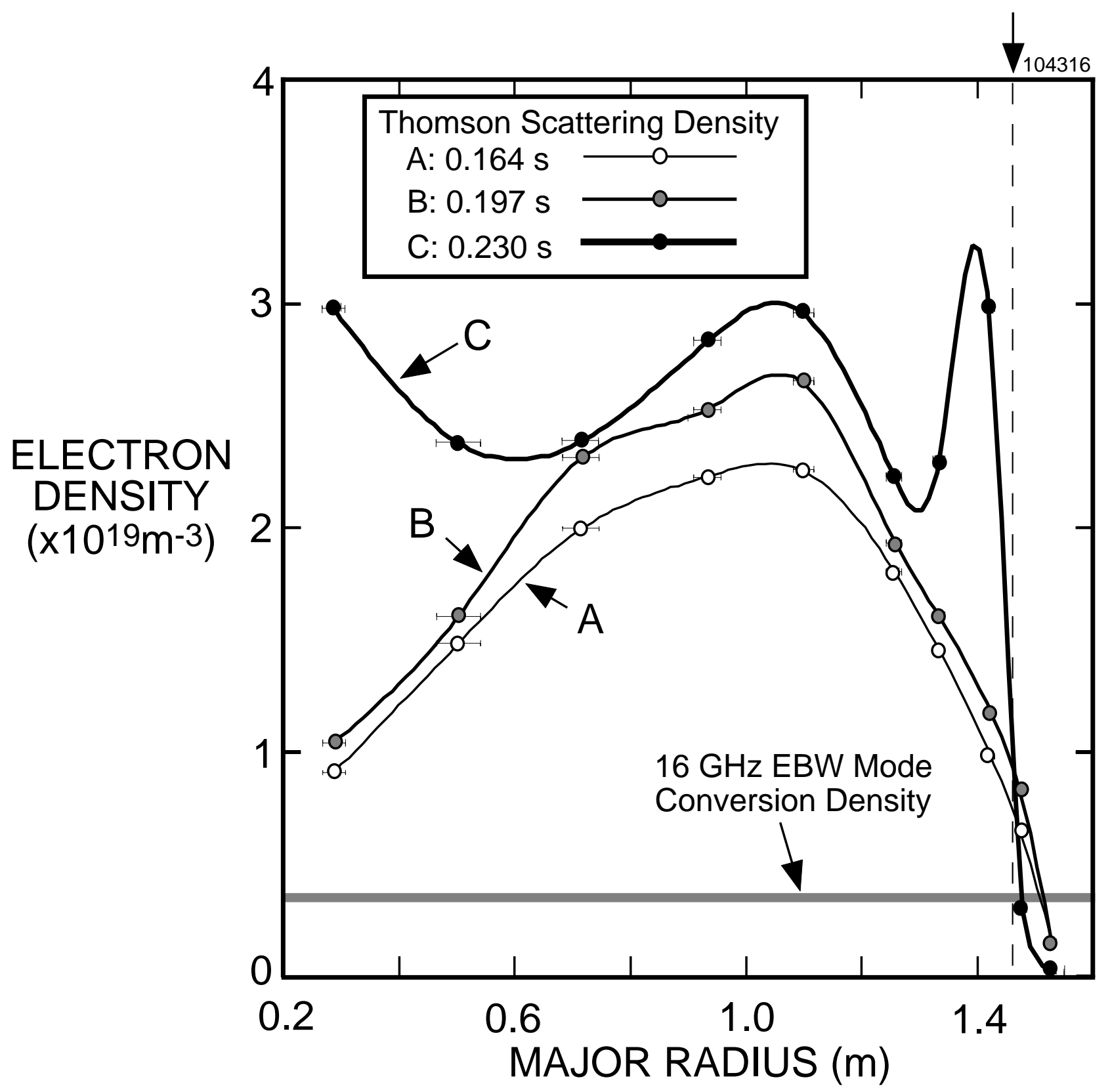




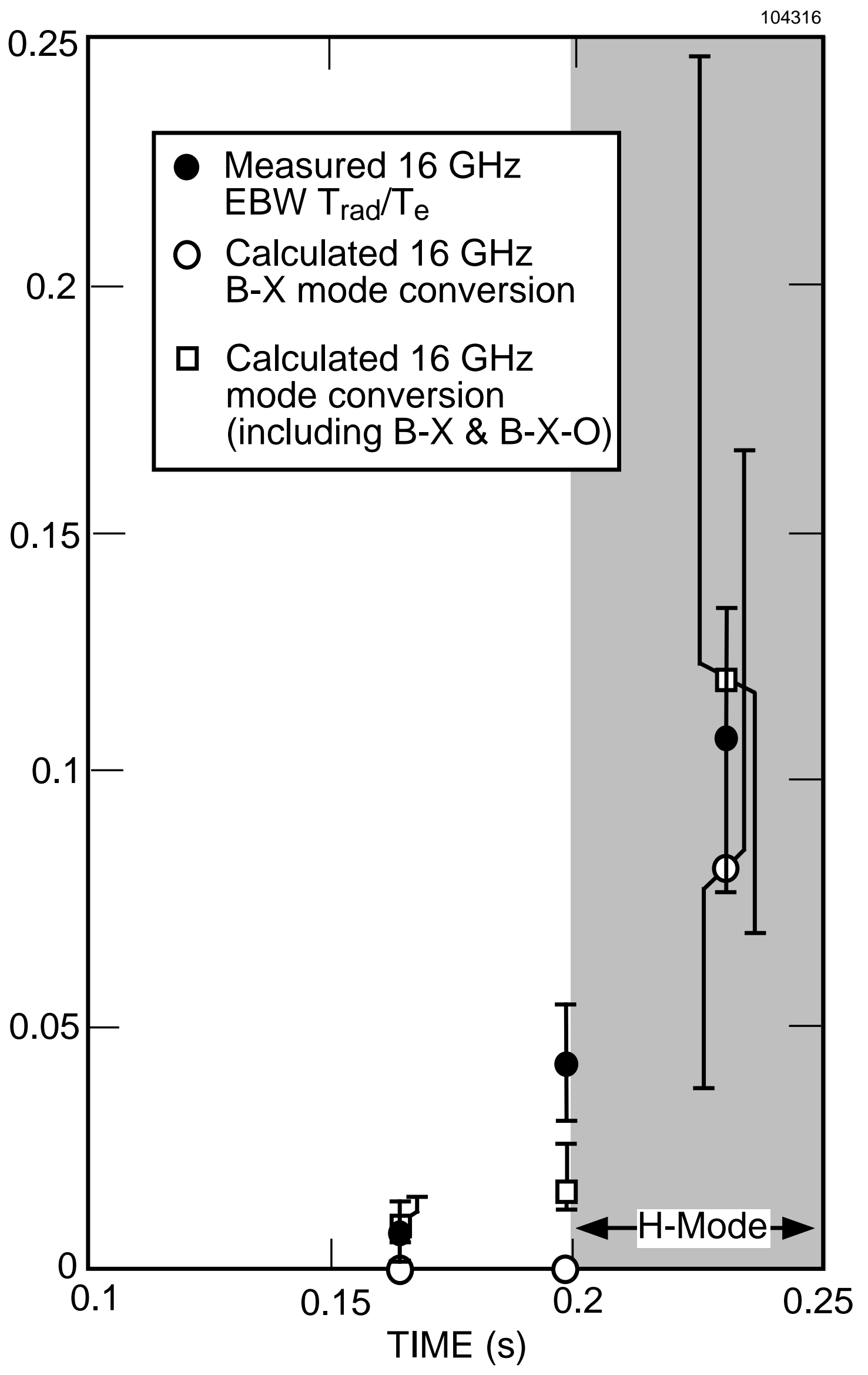




\section{External Distribution}

Plasma Research Laboratory, Australian National University, Australia

Professor I.R. J ones, Flinders University, Australia

Professor J oão Canalle, Instituto de Fisica DEQ/IF - UERJ , Brazil

Mr. Gerson O. Ludwig, Instituto Nacional de Pesquisas, Brazil

Dr. P.H. Sakanaka, Instituto Fisica, Brazil

The Librarian, Culham Laboratory, England

Library, R61, Rutherford Appleton Laboratory, England

Mrs. S.A. Hutchinson, JET Library, England

Professor M.N. Bussac, Ecole Polytechnique, France

Librarian, Max-Planck-Institut für Plasmaphysik, Germany

J olan Moldvai, Reports Library, MTA KFKI-ATKI, Hungary

Dr. P. Kaw, Institute for Plasma Research, India

Ms. P.J . Pathak, Librarian, Insitute for Plasma Research, India

Ms. Clelia De Palo, Associazione EURATOM-ENEA, I taly

Dr. G. Grosso, Instituto di Fisica del Plasma, Italy

Librarian, Naka Fusion Research Establishment, J AERI, J apan

Library, Plasma Physics Laboratory, Kyoto University, J apan

Research Information Center, National Institute for Fusion Science, J apan

Dr. O. Mitarai, Kyushu Tokai University, J apan

Library, Academia Sinica, Institute of Plasma Physics, People's Republic of China

Shih-Tung Tsai, Institute of Physics, Chinese Academy of Sciences, People's Republic of China

Dr. S. Mirnov, TRINITI, Troitsk, Russian Federation, Russia

Dr. V.S. Strelkov, Kurchatov Institute, Russian Federation, Russia

Professor Peter Lukac, Katedra Fyziky Plazmy MFF UK, Mlynska dolina F-2, Komenskeho Univerzita, SK-842 15 Bratislava, Slovakia

Dr. G.S. Lee, Korea Basic Science Institute, South Korea

Mr. Dennis Bruggink, Fusion Library, University of Wisconsin, USA

Institute for Plasma Research, University of Maryland, USA

Librarian, Fusion Energy Division, Oak Ridge National Laboratory, USA

Librarian, Institute of Fusion Studies, University of Texas, USA

Librarian, Magnetic Fusion Program, Lawrence Livermore National Laboratory, USA

Library, General Atomics, USA

Plasma Physics Group, Fusion Energy Research Program, University of California at San Diego, USA

Plasma Physics Library, Columbia University, USA

Alkesh Punjabi, Center for Fusion Research and Training, Hampton University, USA

Dr. W.M. Stacey, Fusion Research Center, Georgia Institute of Technology, USA

Dr. J ohn Willis, U.S. Department of Energy, Office of Fusion Energy Sciences, USA

Mr. Paul H. Wright, Indianapolis, Indiana, USA 
The Princeton Plasma Physics Laboratory is operated by Princeton University under contract with the U.S. Department of Energy.

\author{
Information Services \\ Princeton Plasma Physics Laboratory \\ P.O. Box 451 \\ Princeton, NJ 08543
}

Phone: 609-243-2750

Fax: 609-243-2751

e-mail: pppl_info@pppl.gov

Internet Address: http://www.pppl.gov 